\title{
Sinus node electrogram recording in 59 patients Comparison with simultaneous estimation of sinoatrial conduction using premature atrial stimulation
}

\author{
ALAIN JUILLARD, FRANÇOIS GUILLERM, HUNG VAN CHUONG, ANDRE BARRILLON, \\ ALAIN GERBAUX \\ From the Department of Cardiology, Hopital Boucicaut, Paris, France
}

SUMMARY Directly measured sinoatrial conduction time was compared with sinoatrial conduction time assessed simultaneously by the single premature atrial stimulus technique in 59 patients: 20 with normal sinus function, 35 with sinus dysfunction, and four with sinus bradycardia but negative indirect methods.

In patients with normal sinus function direct sinoatrial conduction time was $102 \cdot 5 \pm 34 \mathrm{~ms}$ (mean \pm 2 SD) and was identical to indirect sinoatrial conduction time. Neither direct sinoatrial conduction time in the basal and return cycle, nor post-return and basal cycle lengths were different. Sinoatrial and atriosinus conduction durations were similar.

In sinus dysfunction direct sinoatrial conduction time (average $160 \pm 47 \mathrm{~ms}$ ) was longer than in normal sinus function. Prolonged direct sinoatrial conduction time may therefore be considered as a criterion of sinus dysfunction.

In sinus dysfunction no significant correlation was observed between direct and indirect sinoatrial conduction times. Direct sinoatrial conduction time was equal to (17 patients), longer than (12 patients), or shorter than (six patients) indirect sinoatrial conduction time. These differences can be explained by delayed or incomplete premature depolarisation penetration into the sinus node rather than by the classical pacemaker shift.

The significance of the data obtained by the single premature atrial stimulus method for the assessment of sinus node function remains uncertain. Sinoatrial conduction time evaluated by this indirect method depends on both atriosinus and sinoatrial conductions. ${ }^{1}$ Premature atrial depolarisation may also cause variability of sinoatrial conduction and/or sinus node automaticity, ${ }^{1}$ especially by shift of the dominant sinus node pacemaker. ${ }^{23}$ Neither the difference between atrial sinus and sinoatrial conduction durations, however, nor variations of sinoatrial conduction induced by premature atrial beat can be assessed by indirect methods.

It is now possible to record sinus node electrical activity in man 4-6; and to study these questions, the single premature atrial stimulus method was compared with the simultaneous sinus node electrogram

Accepted for publication 16 March 1983 recording in patients with and without sinus dysfunction.

\section{Patients and methods}

We attempted to record the sinus node electrogram with simultaneous sinoatrial conduction time evaluation using the single premature stimulus technique in 73 patients over an 11 months period. These patients were submitted to electrophysiological evaluation because of paroxysmal tachycardia and/or suspected paroxysmal atrioventricular block and/or possible sinus dysfunction. All patients gave informed oral consent. No cardioactive drug was administered for at least $\mathbf{4 8}$ hours before the study. The sinus node electrogram was not identified with certainty in 14 patients (19\%), five without and nine with apparent sinus dysfunction.

The remaining 59 patients $(29$ male and 30 female, mean age of 66 years, range 14 to 92 years), were 
included in this study. These patients were divided into three groups.

In group A (20 patients) sinus function was apparently normal; standard electrocardiogram and 24 hour continuous electrocardiograms showed no sinus bradycardia (sinus rate was faster than $60 /$ min except during sleep) and no sinoatrial block (no missing $\mathbf{P}$ wave); the zone of reset was horizontal, indirect sinoatrial conduction time was $130 \mathrm{~ms}$ or less with the single premature atrial stimulus method and with the constant atrial pacing technique, and the longest corrected sinus node recovery time was shorter than 530 $\mathrm{ms}$. The 20 patients in group $\mathrm{A}$ were submitted to electrophysiological evaluation because of paroxysmal ventricular or junctional tachycardia (five patients), paroxysmal second degree atrioventricular block (two patients), or bifascicular bundle-branch block (13 patients).

In group B (35 patients) sinus dysfunction was indicated by the finding of a chaotic zone of reset (six patients), and/or increased indirect sinoatrial conduction time estimated by the single premature atrial stimulus method (26 patients) and/or the constant atrial pacing method (27 patients), and/or prolonged corrected sinus node recovery time (18 patients).

In group C (four patients) permanent sinus bradycardia was associated with negative indirect methods for assessment of sinus node function.

A 6 or 7 French quadripolar electrode catheter (with ring electrodes $10 \mathrm{~mm}$ apart) was inserted into the femoral vein and advanced to the superior vena caval-right atrial junction, as previously described. ${ }^{4-6}$ The distal electrode pair was used to capture the sinus node, and the proximal electrode pair to record high right atrium activity. The recordings were made using an Elema Schönander Siemens Mingograph at a paper speed of $50 \mathrm{~mm} / \mathrm{s}$. Both signals were displayed with the same high amplification ( 50 to $100 \mu \mathrm{V} / \mathrm{cm}$ ) and low pass filter setting (time constant $=0.5 \mathrm{~s}$ ).

A 6 or 7 French USCI bipolar electrode catheter was inserted into the femoral vein and positioned at the upper free wall of the right atrium for pacing with $0.5 \mathrm{~ms}$ duration stimuli, twice the threshold, by means of a Savita orthorhythmic pacemaker.

Sinus node function was studied by three indirect methods similar to those already described. ${ }^{7-9}$ Corrected sinus node recovery time was the difference between return (after prolonged atrial pacing for $\mathbf{3 0}$ seconds) and basal cycle lengths; these procedures were repeated in every patient at the consecutive pacing rates of $90,110,130$, and $150 / \mathrm{min}$ with a free interval of two minutes before each pacing period. Sinoatrial conduction time estimated by the constant atrial pacing method was half the difference between return (after a train of seven consecutive paced beats of $90 \%$ prematurity) and basal cycle lengths. The sinus node function curve ( $x=$ test cycle length, $y=$ return cycle length) was assessed using single premature atrial depolarisations every eight spontaneous sinus beats with $5 \%$ increments in prematurity from $95 \%$ to the atrial refractory period; reset was defined to occur when the sum of the test cycle and return cycle was less than the sum of two spontaneous sinus cycles.

Subsequently single premature atrial depolarisations were delivered in the middle of the reset zone while looking for and recording the sinus node electrogram. The sinus node electrogram was identified using the morphological criteria previously described by Castillo-Fenoy et al.$^{4}$ and Reiffel et al. ${ }^{6}:$ the sinus node electrogram was a smooth low frequency upstroke slope that began before and merged into the atrial wave. The absence of constant preatrial waves on the proximal electrode pair lead indicated that the sinus node electrogram was localised. The variation of the $Q$ wave-sinus node electrogram after premature depolarisation confirmed the lack of relation between the preatrial signal and ventricular activity (Fig. 1 to 4).

In the 59 patients basal, return and post-return cycle lengths were measured (in $\mathrm{ms}$ ). Indirect sinoatrial conduction time estimated by the single premature atrial stimulus method was half the difference between the return and basal cycle length during sinus node electrogram recording (Fig. 3). Direct

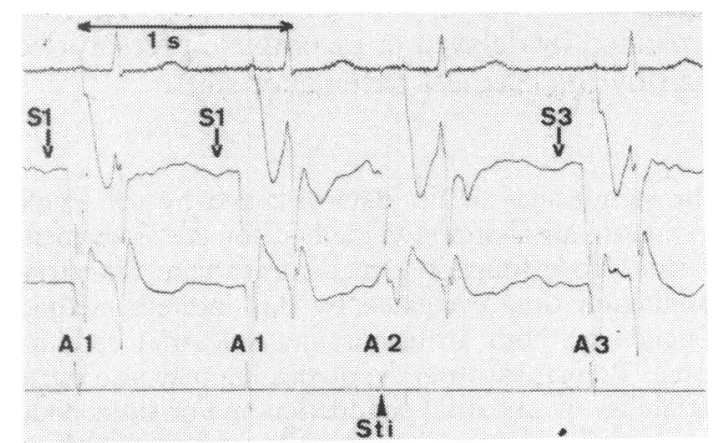

Fig. 1 Simultaneous recording of lead $I(1)$, sinus node $(S)$, and high right atrium $(A)$ during spontaneous rhythm $(A I)$, premature atrial depolarisation in zone of reset (A2), and return cycle (A3). Sti, stimulus. The sinus node electrogram $(S 1, S 3)$ was a smooth upstroke slope which began before and merged into the $A$ wave. In spite of a mild baseline drift no constant preatrial waves were seen in lead $A$; this preatrial signal was obtained only when the catheter was close to the sinus node area. The lengthening of $R$ wave-sinus node electrogram interval after premature depolarisation confirmed the lack of relation between the recorded potential and ventricular activity. In this patient with normal sinus function, the direct sinoatrial conduction time was $100 \mathrm{~ms}$ in the basal and return cycle and was equal to the indirect sinoatrial conducion time. 

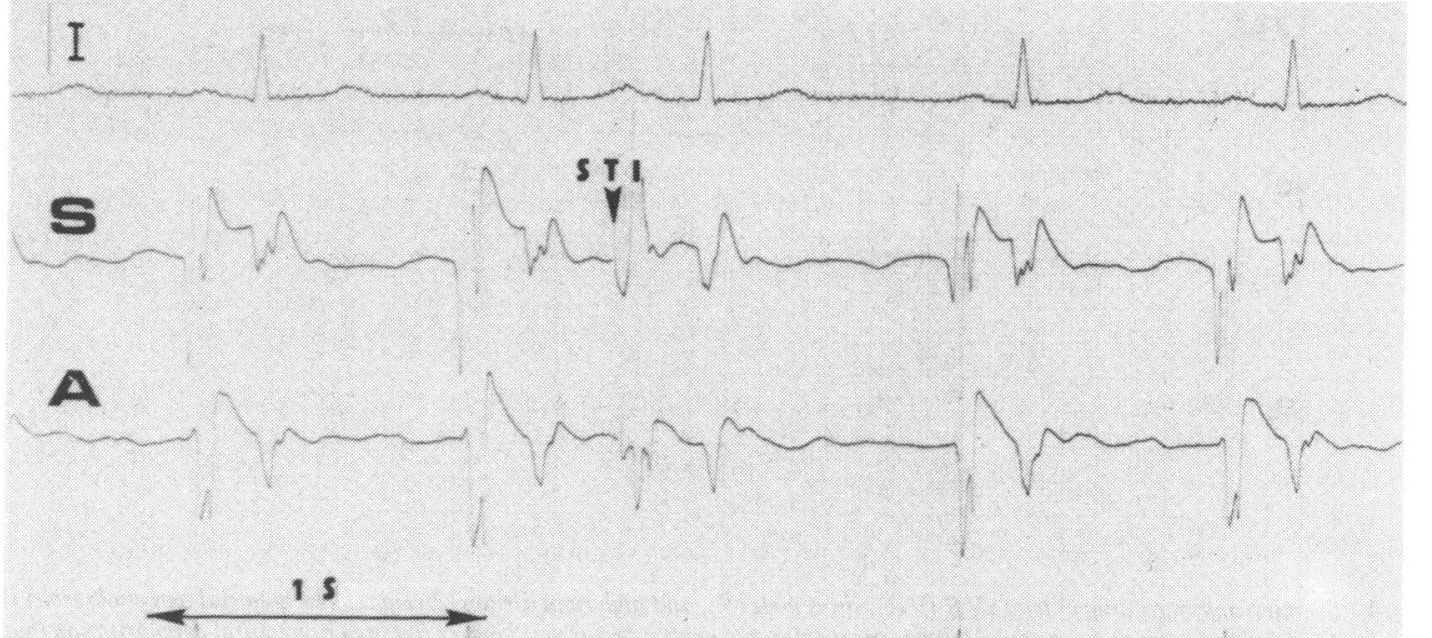

Fig. 2 Simultaneous recording of lead $I$, sinus node $(S)$, and high right atrium $(A)$ leads. STI, stimulus in zone of reset. In spite of a mild baseline drift no constant preatrial waves were seen in lead $A$. In this patient with sinus dysfunction the direct sinoatrial conduction time was $180 \mathrm{~ms}$ in the basal cycle and $190 \mathrm{~ms}$ in the return cycle; it was longer than the indirect sinoatrial conduction time $(130 \mathrm{~ms}) ;$ the basal $(800 \mathrm{~ms})$ and return $(780 \mathrm{~ms})$ cycle lengths were nearly the same. The indirect method failed to indicate the sinoatrial conduction delay. Sinus node penetration by premature atrial depolarisation might have been incomplete.

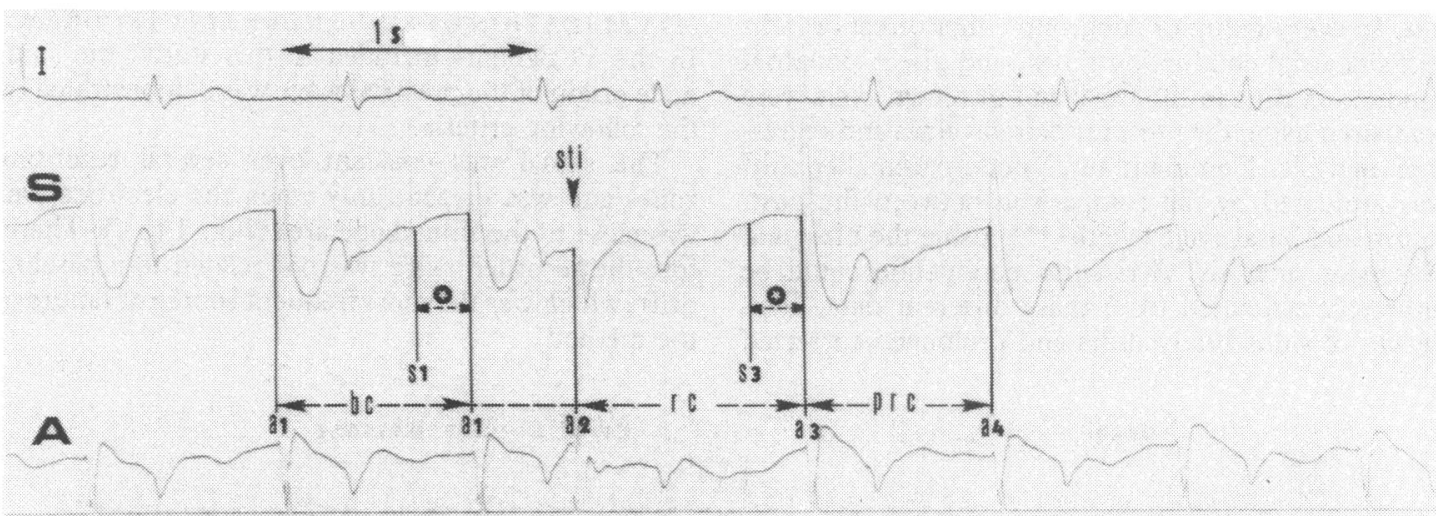

O direct sinostrial conduction time.

Fig. 3 Measurements. Simultaneous recording of lead $I$, sinus node $(S)$, and high right atrium $(A)$ leads. Sti, premature atrial stimulus in zone of reset. In lead A intermittent preatrial waves were noticed, the origin of which is difficult to assess because of the baseline drift; the preatrial signals, however, disappeared with mild shifting of the catheter and were obtained only when the catheter was close to the sinus node area. Direct sinoatrial conduction time was measured from the beginning of the upstroke slope of the sinus node electrogram (s) to the $A$ wave onset (a) for the basal (slal) and return (s3a3) cycles. Basal (bc), return (rc), and post-returm (prc) cycle lengths were measured. Indirect sinoatrial conduction time estimated by the single premature atrial stimulus method was half the difference between $r c$ and bc. Dominant sinus node pacemaker shift was assessed by the comparison between prc and bc.

sinoatrial conduction time was measured using the methods of Reiffel et al. ${ }^{6}$ and Castillo-Fenoy et al. ${ }^{4}$ in the basal and in the return cycle from the beginning of the upstroke slope of the sinus node electrogram to the A wave onset in the same lead, as shown in Fig. 3. The direct and indirect measurements were done separately by two different observers. The onset of the sinus node electrogram was often difficult to define 
S
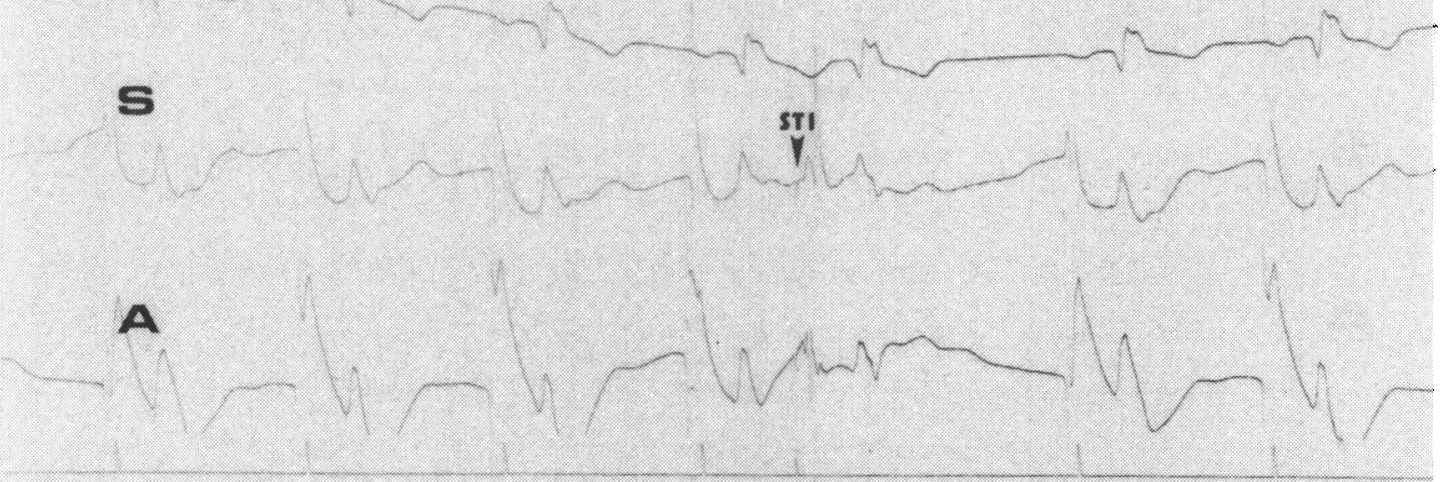

Fig. 4 Simultaneous recording of lead aVR (VR), sinus node $(S)$, and high right atrium $(A)$ leads. The preatrial waves observed in $S$ were not related to ventricular activity: $Q$ wave-preatrial signal onset interval was longer after premature atrial depolarisation than during sinus rhythm. In opposition in $A$ the interval between the $Q$ waves and the preatrial waves (which were intermittent) was the same in the return as in the other cycles: these waves did not originate within the sinus node.

precisely; the interobserver differences, however, in the direct sinoatrial conduction time measurement were $10 \mathrm{~ms}$ or less in most of the patients and never exceeded $20 \mathrm{~ms}$.

Means were evaluated and compared using the $t$ test. In every group or subgroup either direct or indirect sinoatrial conduction times, and direct sinoatrial conduction time in the basal and in return cycle were compared using the $t$ test for paired values and regression analysis. Dominant sinus node pacemaker shift was evaluated by the comparison between the postreturn and basal cycle length ${ }^{2} 1011$ using the $t$ test and regression analysis. Atriosinus conduction could be indirectly estimated from these different data. Incidences of sinus bradycardia and prolonged corrected sinus node recovery time were compared using $\chi^{2}$ test.

\section{Results}

(1) VALIDATION OF SINUS NODE ELECTROGRAM In the 59 patients included in this study, the sinus node origin of the preatrial wave was demonstrated by the following criteria.

The signal was constant over several recording zones and was present only when the electrode pair was close to the sinus node area (Fig. 1 to 4). Therefore the recorded wave was not related to a baseline drift, which was the most frequent source of failure of the method.

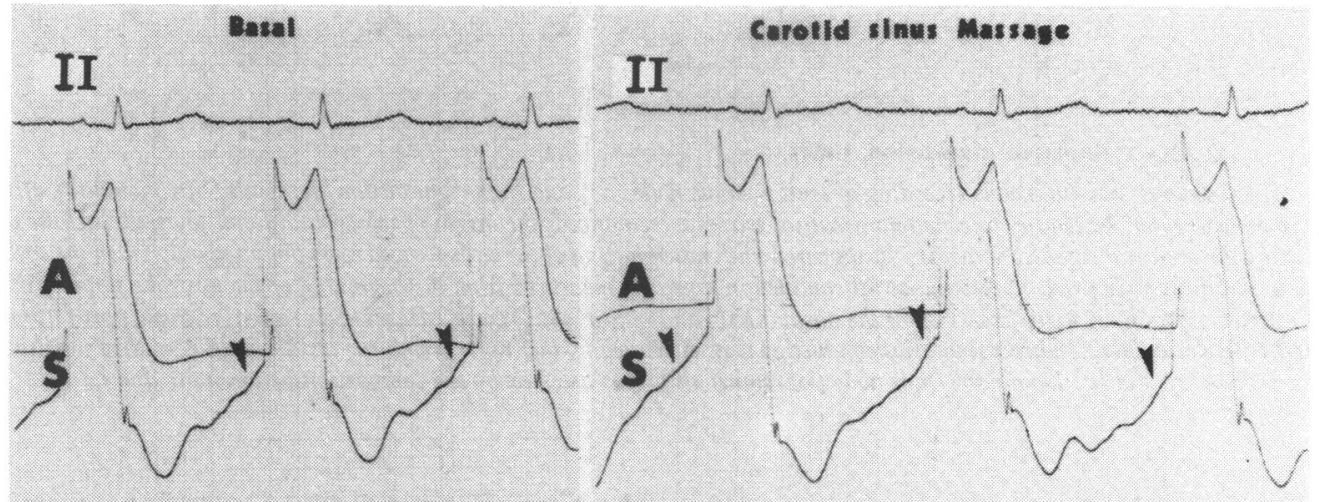

Fig. 5 Simultaneous recording of lead II, sinus node (S), and high right atrium (A) leads before and during carotid sinus massage. Carotid massage induced a lengthening of both sinus cycle and direct sinoatrial conduction time; $Q$ wave-sinus node electrogram (arrows) interval gets longer. 


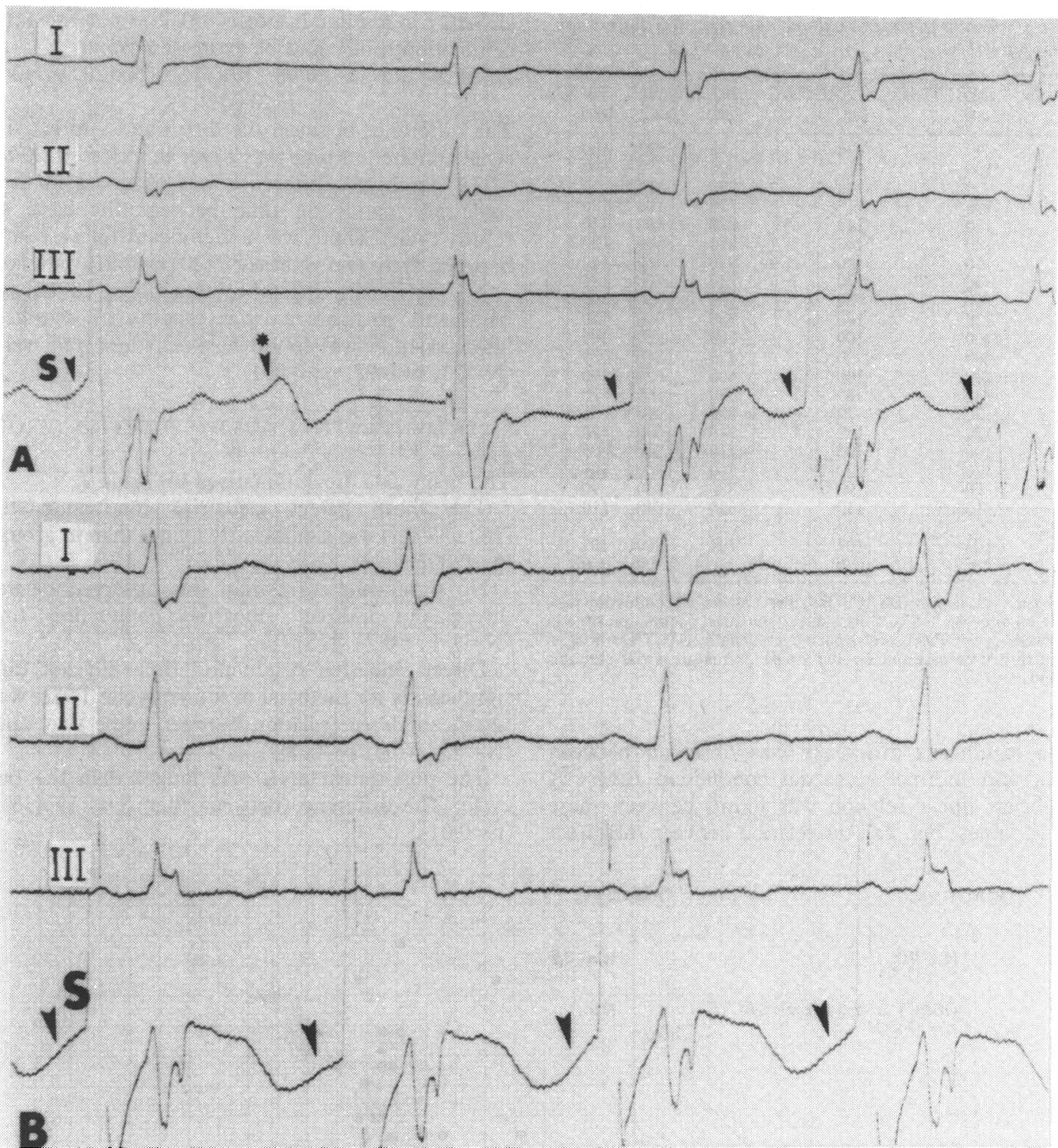

Fig. 6 Simultaneous recording of leads $I, I I$, and III, and sinus node lead during (panel A) and after (panel B) atrial standstill, which was provoked by overdrive suppression. During spontaneous rhythm (panel B) sinoatrial conduction was one to one. During atrial standstill (panel A) the interval between the sinus waves (arrows) got a little longer and a sinus wave was blocked (star) and followed by a junctional escape. Paper speed, $50 \mathrm{~mm} / \mathrm{s}$.

The interval between the $Q$ wave and preatrial wave onset became prolonged after premature atrial depolarisation in the reset zone (Fig. 1 to 4 ). Thus there was no relation between the preatrial wave and ventricular activity.

In addition, it was possible in some patients to induce (using vagal stimulation or overdrive suppression) a block between these signals and $\mathrm{A}$ waves, which confirmed the sinus origin of the recorded potential (Fig. 5 and 6).

(2) PATIENTS WITH NORMAL SINUS FUNCTION (GROUP A)

The main data are summarised in Table 1.

Direct sinoatrial conduction time was $102 \cdot 5 \pm 34 \mathrm{~ms}$ (mean \pm 2 standard deviations), range 70 to $130 \mathrm{~ms}$. 
80

Table 1 Results in patients without apparent sinus dysfunction (group A)

\begin{tabular}{lccccc}
\hline Case No. & $\begin{array}{c}\text { DSACT BC } \\
(\mathrm{ms})\end{array}$ & $\begin{array}{c}\text { DSACT RC } \\
(\mathrm{ms})\end{array}$ & $\begin{array}{l}\text { BC } \\
(\mathrm{ms})\end{array}$ & $\begin{array}{l}\text { PRC } \\
(\mathrm{ms})\end{array}$ & $\begin{array}{c}\text { SACTS } \\
(\mathrm{ms})\end{array}$ \\
\hline 1 & 90 & 90 & 590 & 590 & 100 \\
2 & 100 & 110 & 800 & 780 & 100 \\
3 & 90 & 110 & 890 & 890 & 90 \\
4 & 100 & 110 & 720 & 700 & 100 \\
5 & 120 & 140 & 820 & 840 & 110 \\
6 & 130 & 140 & 850 & 860 & 120 \\
7 & 110 & 110 & 970 & 960 & 110 \\
8 & 130 & 120 & 710 & 700 & 130 \\
9 & 80 & 80 & 730 & 750 & 95 \\
10 & 120 & 140 & 920 & 900 & 120 \\
11 & 100 & 100 & 800 & 800 & 100 \\
12 & 90 & 90 & 820 & 840 & 80 \\
13 & 100 & 100 & 600 & 620 & 100 \\
14 & 80 & 80 & 580 & 560 & 70 \\
15 & 70 & 70 & 880 & 900 & 70 \\
16 & 120 & 120 & 940 & 1000 & 120 \\
17 & 100 & 100 & 710 & 740 & 105 \\
18 & 120 & 120 & 860 & 860 & 105 \\
19 & 90 & 90 & 880 & 860 & 90 \\
20 & 110 & 110 & 820 & 840 & 110 \\
Mean & 103 & 107 & 794 & 800 & 101 \\
SD & \pm 17 & \pm 20 & \pm 114 & \pm 116 & \pm 16 \\
\hline
\end{tabular}

$\mathrm{BC}$, basic cycle length; DSACT BC, direct sinoatrial conduction time in the basal cycle; DSACT RC, direct sinoatrial conduction time in the return cycle; PRC, post-return cycle length; SACTS, sinoatrial conduction time assessed by the single premature atrial stimulus method.

No significant difference was observed between direct and indirect sinoatrial conduction times. A significant linear relation was found between these two variables (Fig. 7a); the relation between the direct
Fuillard, Guillerm, Chuong, Barrillon, Gerbaux

(DSACT in $\mathrm{ms}$ ) and indirect (SACTS in ms) sinoatrial conduction time could be expressed as:

DSACT $=3.5+0.98$ SACTS $(\mathrm{N}=20, \mathrm{r}=0.91$, $\mathrm{p}<0.001$ ).

The difference between the direct and indirect sinoatrial conduction time was never in excess of $20 \mathrm{~ms}$.

No significant difference was observed in direct sinoatrial conduction time between the basal and return cycle. There was a significant linear relation between these two values $(\mathrm{N}=20, \mathrm{r}=0.91, \mathrm{p}<0.001)$.

No significant difference was observed between basal and post-return cycle lengths. A significant linear relation was found between these two values $(\mathrm{N}=20, \mathrm{r}=0.98, \mathrm{p}<0.001)$.

\section{(3) PATIENTS WITH SINUS DYSFUNCTION (GROUP B)}

The main data are summarised in Table 2.

The mean direct sinoatrial conduction time $(160 \pm 47 \mathrm{~ms})$ was significantly longer than in group $A$ $(\mathrm{p}<0.001)$.

No significant correlation was observed between direct and indirect sinoatrial conduction times $(\mathrm{N}=35, \mathrm{r}=0.24$, NS) (Fig. $7 \mathrm{~b}$ ).

Direct sinoatrial conduction time did not differ significantly for the basal or return cycle. There was a significant linear relation between these two values $(\mathrm{N}=35, \mathrm{r}=98, \mathrm{p}<0.001)$.

The post-return cycle was longer than the basal cycle. The difference between them was $19 \pm 33 \mathrm{~ms}$ $(\mathrm{p}<0.01)$.

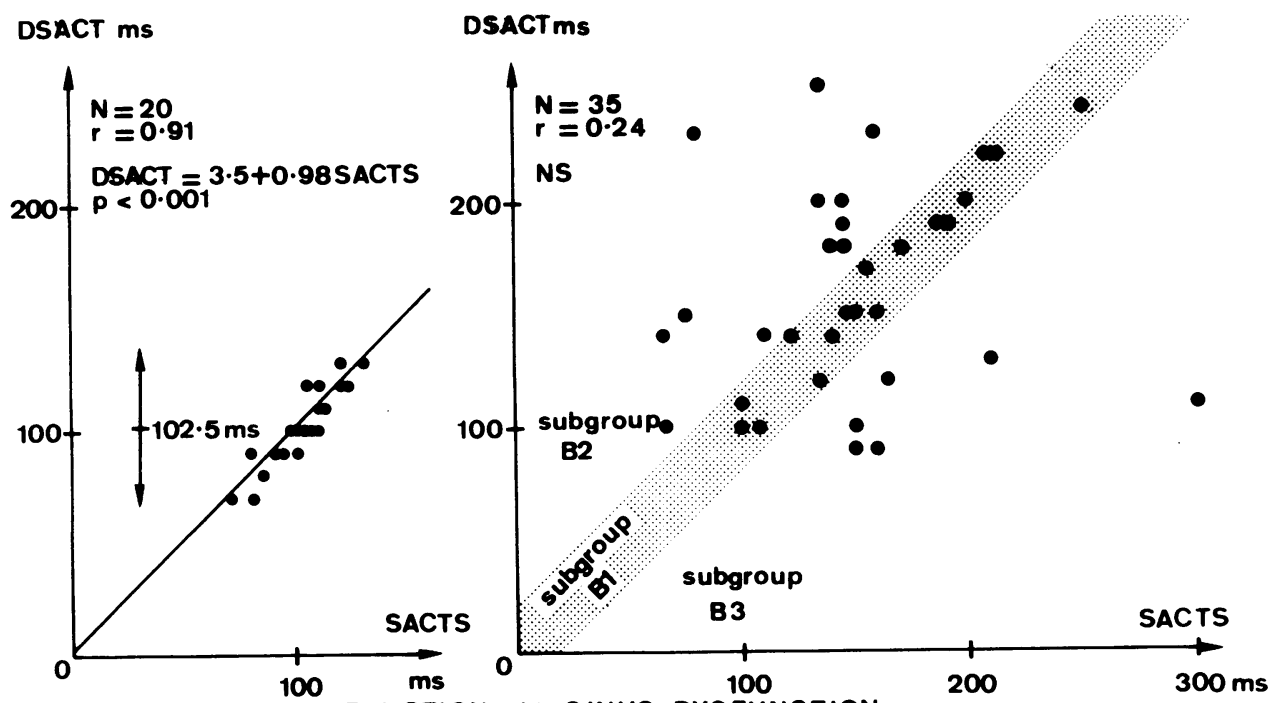

a) NORMAL SINUS FUNCTION b) SINUS DYSFUNCTION

Fig. 7 Correlation between the direct and indirect sinoatrial conduction time: (a) in patients with normal sinus function; (b) in patients with sinus dysfunction. DSACT, direct sinoatrial conduction time; SACTS, indirect sinoatrial conduction time estimated by the single premature atrial stimulus method. 
Table 2 Results in patients with sinus dysfunction (group B)

\begin{tabular}{|c|c|c|c|c|c|}
\hline Case No. & $\underset{\text { (ms) }}{D S A C T B C}$ & $\underset{\text { (ms) }}{\operatorname{DSACT} R C}$ & $\begin{array}{l}B C \\
\text { (ms) }\end{array}$ & $\begin{array}{l}P R C \\
(m s)\end{array}$ & $\begin{array}{l}\text { SACTS } \\
\text { (ms) }\end{array}$ \\
\hline $\begin{array}{l}\text { (a) Subgrc } \\
1 \\
2 \\
3 \\
4 \\
5 \\
6 \\
7 \\
8 \\
9 \\
10 \\
11 \\
12 \\
13 \\
14 \\
15 \\
16 \\
17\end{array}$ & $\begin{array}{l}\text { ap B1 } \\
100 \\
110 \\
220 \\
140 \\
170 \\
190 \\
220 \\
140 \\
150 \\
120 \\
190 \\
240 \\
150 \\
200 \\
100 \\
150 \\
180\end{array}$ & $\begin{array}{l}110 \\
110 \\
240 \\
140 \\
190 \\
180 \\
220 \\
140 \\
150 \\
120 \\
190 \\
240 \\
150 \\
200 \\
100 \\
150 \\
180\end{array}$ & $\begin{array}{r}900 \\
860 \\
1100 \\
660 \\
1080 \\
1220 \\
850 \\
800 \\
880 \\
920 \\
1360 \\
1420 \\
980 \\
940 \\
820 \\
1000 \\
1300\end{array}$ & $\begin{array}{r}920 \\
860 \\
1150 \\
660 \\
1160 \\
1240 \\
900 \\
790 \\
890 \\
940 \\
1380 \\
1480 \\
970 \\
920 \\
830 \\
970 \\
1330\end{array}$ & $\begin{array}{l}110 \\
100 \\
210 \\
140 \\
155 \\
190 \\
210 \\
120 \\
150 \\
135 \\
180 \\
255 \\
160 \\
200 \\
100 \\
150 \\
170\end{array}$ \\
\hline $\begin{array}{l}\text { (b) Subgr } \\
18 \\
19 \\
20 \\
21 \\
22 \\
23 \\
24 \\
25 \\
26 \\
27 \\
28 \\
29\end{array}$ & $\begin{array}{l}\text { up B2 } \\
200 \\
250 \\
150 \\
100 \\
140 \\
200 \\
180 \\
180 \\
230 \\
140 \\
190 \\
230\end{array}$ & $\begin{array}{l}180 \\
250 \\
170 \\
100 \\
140 \\
200 \\
190 \\
180 \\
230 \\
150 \\
200 \\
230\end{array}$ & $\begin{array}{r}940 \\
930 \\
1010 \\
800 \\
850 \\
1140 \\
800 \\
720 \\
1300 \\
940 \\
1510 \\
1140\end{array}$ & $\begin{array}{r}990 \\
950 \\
980 \\
810 \\
850 \\
1150 \\
780 \\
730 \\
1300 \\
1050 \\
1470 \\
1180\end{array}$ & $\begin{array}{r}140 \\
135 \\
75 \\
65 \\
65 \\
145 \\
135 \\
145 \\
40 \\
110 \\
145 \\
160\end{array}$ \\
\hline $\begin{array}{l}\text { (c) Subgrc } \\
30 \\
31 \\
32 \\
33 \\
34 \\
35\end{array}$ & $\begin{array}{c}\text { up B3 } \\
130 \\
120 \\
90 \\
100 \\
90 \\
110\end{array}$ & $\begin{array}{r}150 \\
130 \\
100 \\
90 \\
80 \\
110\end{array}$ & $\begin{array}{r}1030 \\
650 \\
720 \\
760 \\
740 \\
740\end{array}$ & $\begin{array}{r}1060 \\
650 \\
750 \\
800 \\
830 \\
760\end{array}$ & $\begin{array}{l}210 \\
165 \\
160 \\
150 \\
150 \\
300\end{array}$ \\
\hline $\begin{array}{l}\text { Mean } \\
\text { SD }\end{array}$ & $\begin{array}{l}160 \\
\pm 47\end{array}$ & $\begin{array}{l}162 \\
\pm 48\end{array}$ & $\begin{array}{c}966 \\
\pm 221\end{array}$ & $\begin{array}{c}995 \\
\pm 223\end{array}$ & $\begin{array}{l}151 \\
\pm 50\end{array}$ \\
\hline
\end{tabular}

(a) Patients with similar direct and indirect sinoatrial conduction times; (b) patients with longer direct than indirect sinoatrial conduction times; (c) patients with shorter direct than indirect sinoatrial conduction times.

For abbreviations see Table 1.

Group B was divided into three subgroups: B1 made up of 17 patients with similar direct and indirect sinoatrial conduction times (no significant difference), B2 made up of 12 patients in each of whom the direct sinoatrial conduction time exceeded the indirect time by more than $20 \mathrm{~ms}(\mathrm{p}<0.001), \mathrm{B} 3$ made up of six patients in each of whom the direct sinoatrial conduction time was shorter than the indirect time $(p<0.001)$ by more than $20 \mathrm{~ms}$ (Table 2, Fig. 7b).

Direct sinoatrial conduction time was not significantly different between the basal and return cycle in each of the subgroups.

The post-return cycle was longer than the basal cycle in all the subgroups. This difference was significant in subgroups $B 1(18 \pm 30 \mathrm{~ms}, \mathrm{~N}=17$,
Table 3 Results in patients with sinus bradycardia but normal indirect data (group C)

\begin{tabular}{llllll}
\hline Case No. & $\begin{array}{l}\text { DSACT BC } \\
(\mathrm{ms})\end{array}$ & $\begin{array}{l}\text { DSACT RC } \\
(\mathrm{ms})\end{array}$ & $\begin{array}{l}\text { BC } \\
(\mathrm{ms})\end{array}$ & $\begin{array}{l}\text { PRC } \\
(\mathrm{ms})\end{array}$ & $\begin{array}{l}\text { SACTS } \\
(\mathrm{ms})\end{array}$ \\
\hline 1 & 100 & 100 & 1080 & 1100 & 120 \\
2 & 180 & 190 & 1010 & 1060 & 90 \\
3 & 130 & 130 & 1050 & 1060 & 130 \\
4 & 200 & 220 & 1210 & 1220 & 110 \\
\hline
\end{tabular}

For abbreviations see Table 1 .

$\mathrm{t}=2.47, \mathrm{p}<0.05)$ and $\mathrm{B} 3(35 \pm 30 \mathrm{~ms}, \mathrm{~N}=6, \mathrm{t}=2.84$, $p<0.05)$, but not in subgroup $B 2(13 \pm 40 \mathrm{~ms}, \mathrm{~N}=12$, $t=1 \cdot 15)$.

These sinus cycle variations did not differ significantly between subgroups $B 1$ and $B 2(t=0.36)$, between subgroups $B 1$ and $B 3(t=1 \cdot 15)$, or between subgroups $B 2$ and $B 3(t=1.32)$.

The incidence of sinus bradycardia $(7 / 17$ patients in subgroup B1 versus $5 / 12$ patients in subgroup B2) did not differ significantly in the two subgroups $(p<0 \cdot 1)$. Corrected sinus node recovery time was more often prolonged in subgroup B1 (12/17 patients) than in subgroup B2 (4/12 patients) $\left(x^{2}=3.88, p<0.05\right)$. The number of patients in subgroup B3 was considered too small for this $\chi^{2}$ analysis.

\section{(4) PATIENTS WITH SINUS BRADYCARDIA BUT} NORMAL INDIRECT DATA (GROUP C)

The data are summarised in Table 3.

In two patients the direct sinoatrial conduction time was $130 \mathrm{~ms}$ or less and identical to the indirect sinoatrial conduction time. In the other two patients the direct sinoatrial conduction time was prolonged and much longer than the indirect sinoatrial conduction time. The post-return cycle was longer than the basal cycle. No important difference of direct sinoatrial conduction time was observed between the basal and return cycle.

\section{Discussion}

The catheter technique for sinus node electrogram recording was described in 19794 and has been used by several other investigators. ${ }^{5612-14}$ The sinus node origin of the signal was demonstrated by the following. The preatrial waves looked like the sinus node electrograms recorded in the intact $\operatorname{dog} .{ }^{45}$ These signals were found only when the catheter was close to the sinus node. ${ }^{46}$ No relation was observed between these potentials and ventricular activity ${ }^{4}$ (Fig. 4). In addition, carotid sinus massage and/or overdrive suppression could induce a block between these electrograms and A waves, 4513 as shown in Fig. 5 and 6.

Sinus node electrograms may be difficult to obtain, however, especially when the sinus rate is fast (and the $T$ wave is close to the $A$ wave) and when the 
baseline drifts considerably. In the present study a sinus node electrogram was obtained in $80 \%$ of the patients. Reiffel et al. ${ }^{6}$ obtained it in $83 \%$ and Gomes et al. ${ }^{13}$ in $64 \%$ of the cases. In addition, the onset of the sinus node electrogram is often gradual and difficult to define; the interobserver differences in direct sinoatrial conduction time remain, however, slight $^{6}$ and do not exceed $20 \mathrm{~ms}$, but explain that a faster than $50 \mathrm{~mm} / \mathrm{s}$ paper speed is not necessary.

The finding of a normal mean direct sinoatrial conduction time of $102.5 \mathrm{~ms}$ (range 70 to $130 \mathrm{~ms}$ ) is in a similar range to those already reported. 461314 In contrast, much shorter values than ours have been described, 5 but only four of those patients in whom a sinus node electrogram was recorded were more than 14 years old. In addition, the indirect sinoatrial conduction time in normal subjects was found to vary considerably between studies. ${ }^{1}$ This discrepancy might therefore be explained by the difference between the populations studied. Furthermore, in the present study the point of departure of the upstroke slope of the sinus node electrogram was determined using the method proposed earlier. ${ }^{46}$ With this latter method, the onset of the measured interval is usually earlier than with the other technique. 5

In accordance with previous studies ${ }^{13} 14$ direct sinoatrial conduction time was longer in sinus dysfunction that in normal sinus function. A prolonged direct sinoatrial conduction time seems therefore to be a criterion of sinus dysfunction.

In recent works the correlation between the direct and indirect sinoatrial conduction time was found to be either good ${ }^{11^{-13}}$ or absent. ${ }^{14}$ In those studies, however, sinus cycle length and therefore sinoatrial conduction duration might have been different for one method and the other. ${ }^{15}$ Important variations in the direct sinoatrial conduction time can be seen at different times during the same investigation. ${ }^{4}$ This problem was avoided in the present study as the two methods for sinoatrial conduction time assessment were performed simultaneously.

In normal sinus function (group A), as we found previously in 10 patients, ${ }^{15}$ direct and indirect sinoatrial conduction times were identical. Their excellent correlation seems to confirm the hypothesis of Strauss et $a l .{ }^{9}$ Return cycle is the sum of atriosinus conduction plus sinus return cycle plus return sinoatrial conduction (Fig. 8). The basal and post-return cycle lengths did not differ significantly. This fact seems to indicate that atrial premature depolarisation did not cause significant sinus cycle variations or a significant shift of the dominant sinus node pacemaker ${ }^{21011}$ Thus, sinus return cycle duration appears to be nearly the same as basal cycle length, and the difference between return and basal atrial cycle lengths seems to be equal to atriosinus plus sinoatrial conduction durations.
Direct sinoatrial conduction time was found to be equal to half this difference, and to be identical in the basal and in return cycle. Thus atriosinus and sinoatrial conduction durations seem to be similar.

In contrast to our results, other workers ${ }^{3} 1617$ using microelectrodes in the rabbit found that atriosinus conduction duration was shorter than sinoatrial conduction duration; therefore the indirect sinoatrial conduction time was shorter than the true sinoatrial conduction duration. The reason for the delay between sinus node dominant pacemaker activation and sinus node electrogram onset is still unanswered, and the direct sinoatrial conduction time might be shorter than the true sinoatrial conduction duration. In those animal studies, however, the prematurity of stimulation was insignificant, whereas in the present study the premature atrial depolarisations were delivered in the middle of the reset zone; now atriosinus conduction duration became longer with increasing prematurity ${ }^{17}$; and during constant overdrive in the rabbit, atriosinus conduction duration was found to be even longer than sinoatrial conduction duration. ${ }^{18}$ In addition, the differences between our results and those of most earlier animal works might be related to the presence in the rabbit of an anatomically individualised sinoatrial junction ${ }^{19}$ which has never been observed in man.

In sinus dysfunction (group B) no correlation was found between direct and indirect sinoatrial conduction times. Compared with indirect time, direct sinoatrial conduction time was nearly the same in 17 patients (subgroup B1), but was longer in 12 patients (subgroup B2) and shorter in six (subgroup B3). The single premature atrial stimulus technique for sinoatrial conduction time assessment therefore appears to be unreliable in patients with sinus dysfunction.

Direct sinoatrial conduction time did not differ between the basal and return cycle, either for group B as a whole or in each of its subgroups. Thus, the

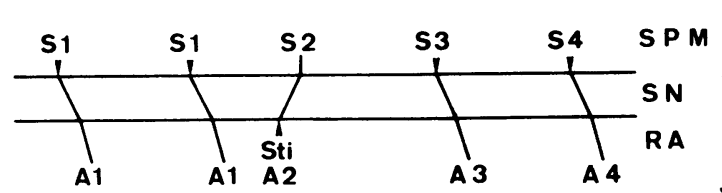

Fig. 8 Patients with normal sinus function: atriosinus and sinoatrial conduction durations are similar. Arrows indicate the onset of depolarisation in the sinus node pacemaker (SPM) for basal (1), returm (3), and post-return (4) cycles, or in the right atrium (RA) for paced cycle (2). S, sinus node pacemaker depolarisation; $A$, atrial depolarisation onset; $S N$, sinus node. $A 3 A 4$ was approximately equal to $A 1 A 1$, therefore $S 2 S 3$ was held to be close to A1A1. SIAI and S3A3 were identical and $S 1 A 1$ was equal to half the difference between $A 2 A 3$ and $A 1 A 1$. Thus, S1A1 and A2S2 seem close. 
discrepancies between the two methods do not seem to result from atrial premature depolarisation-induced variations in sinoatrial conduction.

In group B the post-return cycle was longer than the basal cycle. The premature depolarisation in reset zone appeared to induce routinely a centrifugal shift of the dominant sinus node pacemaker. ${ }^{2}$ The sinus cycle length variations, however, did not differ between one subgroup and another. Therefore (in spite of the groups' inhomogeneity) the discrepancies between the methods cannot be explained solely by a shift of the dominant sinus node pacemaker, and sinus node penetration by premature depolarisation is questionable.

In patients with longer indirect than direct sinoatrial conduction time, atriosinus conduction might have been delayed (Fig. 9).

In patients with shorter indirect than direct sinoatrial conduction time (Fig. 10), sinus node penetration by premature depolarisation could have been incomplete (with electrotonically induced variations of sinus node pacemaker activity), as Bonke et al. ${ }^{20}$ previously noticed in the rabbit. Corrected sinus node recovery time was more often prolonged in subgroup B1 than in subgroup B2. This difference might also be explained by incomplete sinus node penetration during rapid atrial pacing in subgroup B2, as shown in the rabbit by Kerr and Strauss. ${ }^{21}$

In subgroup B3 all the patients had normal direct but prolonged indirect sinoatrial conduction time. In

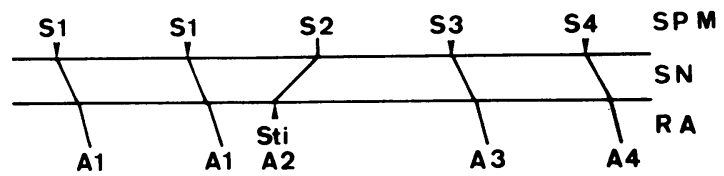

Fig. 9 Patients with shorter direct than indirect sinoatrial conduction time (subgroup B3). Same abbreviations as in Fig. 8. $S 1 A 1$ and S3A3 were identical. The variation of sinus rate from the basal to post-return cycle was similar in patients in whom direct sinoatrial conduction time was equal to, longer than, or shorter than indirect sinoatrial conduction time. Atriosinus conduction might have been delayed.

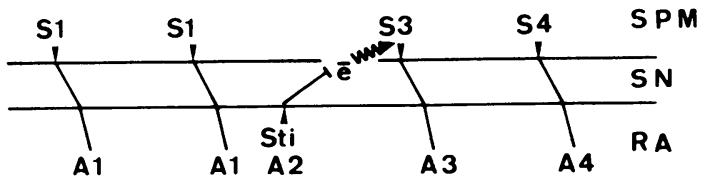

Fig. 10 Patients with longer direct than indirect sinoatrial conduction time (subgroup B2). Same abbreviations as in Fig. 8. The same reasoning as in Fig. 9 leads to the conclusion that sinus node penetration by premature atrial depolaristion might have been incomplete with electrotonically induced variations of sinus node pacemaker activity. this case the question of false positive results with the indirect method is still to be answered.

Prolonged direct sinoatrial conduction time was associated with normal indirect sinoatrial conduction time assessed by the single premature atrial stimulus method in six patients (four in subgroup B2 and two in group $C$ ). In these patients the single premature atrial stimulus method failed to indicate any sinoatrial conduction delay.

\section{Conclusions}

In normal sinus function direct and indirect sinoatrial conduction times were identical. Premature atrial depolarisation in zones of reset seemed to induce neither variation of sinoatrial conduction nor important dominant sinus node pacemaker shift. Atriosinus and sinoatrial conduction durations seem to be similar.

In sinus dysfunction directly measured sinoatrial conduction time was overestimated in $17 \%$ of the patients and underestimated in $37 \%$ of the patients by the single premature atrial stimulus method. The discrepancies between the direct and indirect method for sinoatrial conduction time assessment can be explained by delayed or incomplete premature depolarisation penetration into the sinus node rather than by the pacemaker shift.

The only data which can be used for assessment of sinus node pacemaker shift concern the post-return but not the return cycle. Atriosinus conduction cannot be estimated by indirect methods. Therefore sinus node electrogram recording seems to be the more suitable method for the evaluation of sinoatrial conduction, especially in sinus dysfunction. Since a sinus node electrogram proved doubtful or unobtainable, however, in $19 \%$ of our patients, improvements are yet to be made in the method of recording sinus node electrical activity.

A prolonged direct sinoatrial conduction time seems to be an indicator of sinus dysfunction. Further studies are needed to determine the clinical and prognostic value of such a finding.

We are grateful to Dr C Morlay and D Rogers for their help in the English translation of the manuscript. This work was supported by the Bourse de recherche en rythmologie Labaz which was awarded by the Féderation Française de Cardiologie in 1981.

\section{References}

1 Hariman RJ, Hoffman BF. Method for recording electrical activity of the sinoatrial node in human subjects. The author's reply [letter]. Am f Cardiol 1981; 48: 977-8. 
2 Steinbeck G, Lüderitz B. Sinoatrial pacemaker shift following atrial stimulation in man. Circulation 1977; 56: 402-9.

3 Steinbeck G, Allessie MA, Bonke FIM, Lammers WJEP. Sinus node response to premature atrial stimulation in the rabbit studied with multiple microelectrode impalements. Circ Res 1978; 43: 695-704.

4 Castillo-Fenoy A, Thebaut JF, Achard F, De Langenhagen B. Le potentiel du noeud sinusal de Keith et Flack. Technique d'enregistrement chez l'homme. Résultats préliminaires. Coeur Med Interne 1979; 18: 77-81.

5 Hariman RJ, Krongrad E, Boxer RA, Weiss MB, Steeg $\mathrm{CN}$, Hoffman BF. Method for recording electrical activity of the sinoatrial node and automatic atrial foci during cardiac catheterization in human subjects. Am $\mathcal{f}$ Cardiol 1980; 45: 775-81.

6 Reiffel JA, Gang E, Gliklich J, et al. The human sinus node electrogram: a transvenous catheter technique and a comparison of directly measured and indirectly estimated sinoatrial conduction time in adults. Circulation 1980; 62: 1324-34.

7 Mandel W, Hayakawa H, Danzig R, Marcus HS. Evaluation of sino-atrial function in man by overdrive suppression. Circulation 1971; 44: 59-66.

8 Narula OS, Shantha N, Vasquez M, Towne WD, Linhart JW. A new method for measurement of sinoatrial conduction time. Circulation 1978; 58: 706-14.

9 Strauss HC, Saroff AL, Bigger JT Jr, Giardina EGV. Premature atrial stimulation as a key to the understanding of sinoatrial conduction in man. Presentation of data and critical review of the literature. Circulation 1973; 47: 86-93.

10 Breithardt G, Seipel L. The effect of premature atrial depolarization on sinus node automaticity in man. Circulation 1976; 53: 920-5.

11 Dhingra RC, Wyndham C, Amat-y-Leon F, Denes P, Wu D, Rosen KM. Sinus nodal responses to atrial extrastimuli in patients without apparent sinus node disease. Am $\mathcal{F}$ Cardiol 1975; 36: 445-52.

12 Rakovec P, Jakopin J, Rode P, Kenda MF, Horvat M. Clinical comparison of indirectly and directly determined sinoatrial conduction time. Am Hean f 1981; 102: 292-4.
13 Gomes JAC, Kang PS, El-Sherif N. The sinus node electrogram in patients with and without sick sinus syndrome: techniques and correlation between directly measured and indirectly estimated sinoatrial conduction time. Circulation 1982; 66: 864-73

14 Padeletti L, Michelucci A, Fradella GA, Brat A, Frantini F. Evaluation du temps de conduction sinoauriculaire par enregistrement du potentiel du noeud sinusal. Comparaison avec les méthodes indirectes d'évaluation. Arch Mal Coeur 1982; 75: 1233-9.

15 Juillard A, Guillerm F, Chuong HV, et al. Enregistrement du potentiel sinusal: confrontation aux méthodes indirectes d'évaluation de la fonction sinusale chez 10 patients indemnes de dysfonction sinusale. Arch Mal Coeur 1982; 75: 1225-32.

16 Cramer M, Siegal M, Bigger JT Jr, Hoffman BF. Characteristics of extracellular potentials recorded from the sinoatrial pacemaker of the rabbit. Circ Res 1971; 41: 292-300.

17 Miller HC, Strauss HC. Measurement of sinoatrial conduction time by premature atrial stimulation in the rabbit. Circ Res 1974; 35: 935-47.

18 Sano T, Yamagishi S. Spread of excitation from the sinus node. Circ Res 1965; 16: 423-30.

19 Tranum-Jensen J. The fine structure of atrial and atioventricular junctional specialized tissues of the rabbit heart. In: Wellens HJ, Lie KI, Janse MJ, eds. The conduction system of the heart. Philadelphia: Lea and Febiger, 1976

20 Bonke FIM, Bouman LN, Schopman FJG. Effect of an early atrial premature beat on activity of the sinoatrial node and atrial rhythm in the rabbit. Circ Res 1971; 29: 704-15.

21 Kerr CR, Strauss HC. The nature of atriosinus conduction during rapid atrial pacing in the rabbit heart. Circulation 1981; 63: 1149-57.

Requests for reprints to Dr A Juillard, Service de Cardiologie, Hopital Boucicaut, 78 rue de la Convention, 75015 Paris, France. 